\title{
Associações rurais e associativismo no Nordeste amazônico: uma relação nem sempre correspondida
}

Maria Cristina Maneschy - Doutora em Sociologia pela Université Toulouse Le Mirail, França. Atualmente é professora adjunto da UFPA.

Maria Lúcia Sá Maia - Mestre em Planejamento do Desenvolvimento.

Maria de Fátima Carneiro da Conceição - Doutora em Sociologia pela Universidade de São Paulo - USP. Atualmente é professora adjunto da UFPA.

\section{Resumo}

O presente estudo, feito em 2005, baseia-se em entrevistas com líderes de quarenta e três associações do Nordeste do Estado do Pará. Constatou-se que essa modalidade jurídica de cooperação, oficialmente privilegiada, tem passado ao largo das formas de organização espontâneas consagradas pela tradição camponesa e firmadas em laços de confiança, fidelidade e co-responsabilidade. As associações estudadas, muitas vezes, resumiam-se a meros grupos formais, e a elas cumpria estabelecer ou acompanhar contratos entre instituições financeiras, organizações públicas e privadas e os grupos camponeses. As associações que melhor alcançavam os resultados econômicos, políticos ou culturais almejados eram as que tinham vivenciado, anteriormente a sua constituição, algumas atividades coletivas ou comunitárias, isto é, aquelas que já tinham praticado uma forma de associativismo envolvendo um compromisso efetivo entre os membros. Essas contradições, vividas pelas comunidades tradicionais na ocasião de sua inserção no sistema institucional moderno, merecem atenção.

\section{Palavras-chave}

Associações; grupos camponeses; cooperação; capital social; crédito rural.

\begin{abstract}
This study was undertaken in 2005 and is founded on interviews with leaders of fortythree rural associations in four municipalities from the northeastern part of the State of Pará. It observed that generally such institutional forms of cooperation, officially supported, have not matched the spontaneous forms of cooperation, according to peasant traditions and rooted in trust and mutual responsibility. Frequently, associations that were just formal had to engage into agreements or to follow agreements between financial institutions, public and private organizations and the peasant producers. Associations with more effective economic, political or cultural outcomes were those that had, prior to their constitution, implemented collective or community activities, kinds of associations based on shared commitments and trust. These contradictions that traditional communities experience when they participate in the modern institutional system merit attention.
\end{abstract}

\section{Keywords}

Associations; peasant groups; cooperation; social capital; rural credit. 


\section{INTRODUÇÃO}

$\mathrm{Na}$ Amazônia, os grupos camponeses apresentam uma notável diversidade (ALMEIDA, 1994; CARVALHO, 2005). São pescadores artesanais, agricultores, ribeirinhos, quilombolas, moradores em unidades de conservação, extrativistas, sem falar nas comunidades indígenas, que exibem variadas formas de cooperação, tradicionais e novas. Nos últimos anos, chama a atenção entre esses grupos a difusão acelerada de uma forma específica, oficialmente privilegiada, de cooperação: a forma jurídica de "associação".

Essas associações locais de grupos camponeses são alvo de políticas públicas e de programas de agências de desenvolvimento. Programas de crédito, assistência técnica, qualificação e acesso ao território estimulam sua formação (CONTENTE, 2007; COSTA, 2006; MAIA; NEVES, 2002; TURA, 2002). A participação na administração de reservas ambientais, especialmente das reservas extrativistas, também tem sido subordinada à filiação a associações de moradores e usuários (ESTERCI; LIMA; LÉNA, 2002; HÉBETTTE, 2006; MOREIRA, 2006).

Essa difusão no meio rural de uma região como a Amazônia tem a ver com o fato de a sua população rural ser bem superior à média nacional - 30\% e $18 \%$ da população total, respectivamente - e com a falta de oportunidades de inserção no setor formal da economia para amplos contingentes populacionais, tanto urbanos quanto rurais. Ademais, seguindo uma tendência internacional nos discursos sobre desenvolvimento e meio ambiente, sublinha-se o valor de promover, ao lado de uma presença estatal efetiva no vasto território amazônico, o respeito pelas diferenças, a participação da sociedade e as "associações que contribuam para formar capital social” (BRASIL, 2004). Essa abordagem que valoriza a participação vai de par com o reconhecimento das falências e dos custos sociais e ambientais do padrão autoritário de desenvolvimento regional prevalecente até hoje, a despeito dos atenuantes e das precauções.

Com efeito, a propagação de organizações no campo vincula-se a enunciados de participação, descentralização e valorização do nível local da ação. Tais dimensões estão presentes nos discursos e em programas do Estado e das agências internacionais de desenvolvimento, assim como de organizações não governamentais (ONG) (HÉBETTE, 2004; SCHUURMAN, 2003; SZRETER; WOOLCOCK, 2004; WOOLCOCK; NARAYAN, 2000). Em consonância, o valor da presença da sociedade 
civil no desenho e na implemen-tação de políticas de desenvolvimento local tem sido reconhecido e discutido (DAGNINO, 2002; LAVALLE; CASTELLO; BICHIR, 2007; ROBERTS, 2005; SILVA, 2006). Como em outros contextos nacionais, há também aqui um apelo ao "empreendedorismo" de comunidades ou grupos sociais em desvantagem, na sua busca de recursos diversos e de participação em decisões.

Contudo, costuma ser grande a distância entre, de um lado, a celebrada valorização da ação local e seu papel na consolidação da democracia e, de outro, a prática em diferentes contextos sociais. Uma questão crítica diz respeito à adequação da multiplicidade de formas de ação coletiva enraizadas em culturas, histórias complexas e diferenciadas às exigências dos instrumentos de fomento por parte do Estado e de diferentes instituições. Enquadramento e uniformização podem, pois, contrapor-se à flexibilidade de formas de cooperação que justamente tem possibilitado a existência dos grupos sociais e suas relações de confiança, com consequências que precisam ser consideradas.

Esse é o foco do presente artigo, que se baseia em resultados da pesquisa Participação Política em Associações Rurais na Amazônia Oriental (EPAR), desenvolvida entre 2004 e 2005․ Toma-se aqui a experiência de quarenta e três associações em quatro municípios do Nordeste do Estado do Pará em que a pesca artesanal praticada nos rios, no litoral e nas reservas extrativistas marinhas e a secular agricultura familiar sobressaem na economia.

\section{METODOLOGIA E CARACTERIZAÇÃO DA AMOSTRA}

Os dados da pesquisa foram obtidos em entrevistas semidiretivas com os dirigentes de associações e em observações no local. As entrevistas objetivaram traçar a trajetória da associação, os grupos envolvidos na sua criação e seus motivos, as atividades em curso e as planejadas e as fontes de suporte. Solicitava-se também do entrevistado uma avaliação dos resultados até então alcançados.

O trabalho de campo envolveu cerca de $90 \%$ das associações rurais em três dos municípios, com base nas informações fornecidas pelas instituições pertinentes. No quarto município, levantaram-se os dados em

\footnotetext{
${ }^{1}$ Projeto apoiado pelo Conselho Nacional de Desenvolvimento Científico e Tecnológico (CNPq) e pelo Programa Integrado de Apoio ao Ensino, Pesquisa e Extensão (PROINT) da Universidade Federal do Pará (UFPA).
} 
seis associações na sede municipal, das quais três eram "associações-mãe" que congregavam associações nas diversas comunidades do interior e ilhas do município. A amostra incluiu associações de diferentes tipos, e a frequência de cada tipo procurou corresponder à frequência com que ocorriam nas áreas de pesquisa (Figura 1). Para preservar o anonimato das associações, os nomes citados no texto são fictícios.

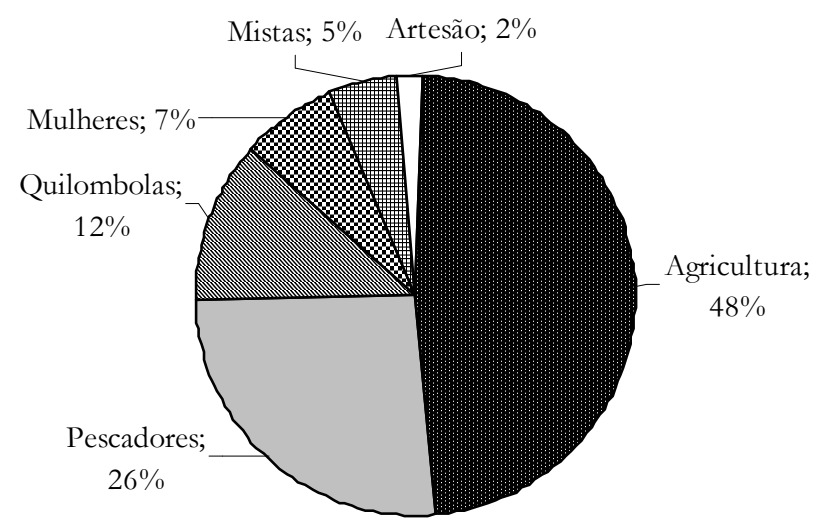

Figura 1: Associações por tipo e frequência.

Vale notar que uma associação de pescadores, uma mista e duas de mulheres localizavam-se em reservas extrativistas recém-criadas na área costeira de dois municípios. As cinco associações de quilombolas pesquisadas estavam em comunidades com estatuto de remanescentes de quilombolas reconhecido e tinham-se formado para representação junto às instituições externas.

Para a discussão aqui proposta sobre as implicações dos processos de indução à formação de associações, este texto examina como elas se constituíram, sob que influências, quais as relações mantidas com grupos ou associações anteriores, os principais objetivos e os interlocutores nessa busca, assim como os caminhos percorridos para alcançá-los. A pesquisa baseou-se nas percepções dos dirigentes, atores tidos como privilegiados por seu envolvimento geralmente antigo na organização, quando não haviam sido eles próprios parte do grupo fundador. Ao longo do texto, trechos das entrevistas são apresentados. Pretendeu-se apreender como os grupos que se associavam interpretavam o que vivenciavam e como procuravam agir; daí a pesquisa ter-se centrado nas associações e não nos seus 'parceiros', dentre os quais se destacavam as organizações governamentais e não governamentais das quais esperavam obter recursos de vários tipos. 


\section{RESULTADOS E DISCUSSÃO}

\subsection{Associações sem associativismo?}

Um poderoso indutor da criação de associações formais nessa região tem sido o acesso ao crédito bancário. Dois terços das pesquisadas haviam-se constituído em função de um requisito das agências financiadoras, especialmente governamentais, como o Banco da Amazônia (BASA) e o Banco do Brasil, tendo em vista a obtenção de financiamento por meio de programas, como o Fundo Constitucional do Norte (FNO) e o Programa Nacional de Fortalecimento da Agricultura Familiar (PRONAF), para agricultura, pecuária, extrativismo vegetal e animal (TURA, 2002). Em um dos municípios, esse requisito de estar em associação condicionou recentemente a cessão, mediante o fornecimento de combustível pela associação, de um trator repassado à prefeitura pelo PRONAF para uso por pequenos agricultores.

Em que pesem a adoção induzida dessa forma de cooperação e as formalidades legais pertinentes, a busca dos financiamentos oficiais espalhou-se aceleradamente, em razão de suas vantagens econômicas. Os pequenos produtores foram frequentemente incentivados a buscar esses financiamentos por outras organizações governamentais, como a Empresa de Assistência Técnica e Extensão Rural (EMATER), por prefeituras, por autarquias como o Serviço de Apoio às Micros e Pequenas Empresas (SEBRAE), por organizações profissionais rurais, como sindicatos ou colônias de pescadores - e, não raro, por políticos locais, como vereadores, candidatos e seus assessores.

Ora, essa forma jurídica de cooperação muitas vezes passava ao largo das formas espontâneas e gratuitas de cooperação consagradas pela tradição camponesa - ajuda interna em família extensa, mutirão, trocas de dias -, baseadas em laços de confiança, fidelidade e co-responsabilidade (MENDRAS, 1978). Os requisitos burocráticos comumente desconheciam as diferenças intrínsecas de lógica econômica e social própria de uma e de outra prática.

Em estudos anteriores, D’Incao (2000), Hébette, Alves e Quintela (2002) e Roy (2002) observaram algumas contradições entre formas novas de interferência externa nas comunidades rurais do Sudeste paraense e sua lógica tradicional. É o caso, por exemplo, da introdução entre migrantes nordestinos naquela região do novo sindicalismo dos trabalhadores rurais, em contraposição às práticas de organização que 
eram, de um lado, organizadas segundo relações comunitárias e, de outro, influenciadas pelo clientelismo.

A literatura sociológica sobre populações tradicionais não tem prestado suficiente atenção a essas contradições vividas pelas comunidades tradicionais na ocasião de sua inserção no sistema institucional moderno, confundindo, às vezes, semanticamente e na prática, "associação legal" e "associativismo" e levando a pensar que associação legal signifique automaticamente associativismo (HÉBETTTE, inédito). Não é de estranhar, portanto, que a experiência das associações tenha sido marcada por problemas que mais complicaram do que facilitaram a esperada relação entre difusão de associações e difusão do associativismo.

Esse fenômeno de associativismo tem, sim, sido objeto de uma literatura expressiva, principalmente americana, representada, notadamente, por teóricos do capital social, como Lin (2001) e Putnam (2002, 2005) e, antes deles, por Coleman (1988). Muito importa, para evitar equívocos, notar que, ao falar de associações, esses autores - tal como seu predecessor no estudo da sociedade americana do século XIX, Tocqueville (Da democracia na América, cap. 9) - focalizaram particularmente a livre e espontânea cooperação de pessoas, independentemente de intervenção da lei.

Boa parte da extensa literatura que hoje utiliza o conceito de capital social toma-o para realçar uma qualidade das redes de relações sociais, isto é, do conjunto das relações que um indivíduo ou grupo mantém com outros e a forma dessas relações (DEGENNE; FORSÉ, 1999). Fontes de normas, de colaboração e de reciprocidade, redes de relações são vistas como geradoras ou facilitadoras do acesso a recursos sociais pelos envolvidos, eventualmente conversíveis em capital econômico e oportunidades sociais e, portanto, coadjuvantes em processos de desenvolvimento e de construção de sociedades democráticas. Destacase seu potencial para fertilizar políticas públicas, dado o poder de pressão 'de baixo para cima' que grupos organizados podem exercer sobre tomadores de decisão.

O conceito de capital social, que nessa ótica aproxima-se do conceito de associativismo, tem sido empregado também em referência à participação de comunidades rurais nos processos de gestão de recursos naturais e de combi-nação entre produção agrícola e conservação do meio ambiente. Exemplos desse emprego são os estudos de Pretty e Ward (2001), Grafton (2005) e Plummer e Fitzgibbon (2006). Para efeito deste 
artigo, é interessante enfatizar o fato de que, com base em extensa revisão bibliográfica, esses autores apontam a correlação entre desaparecimento ou deterioração de estruturas institucionais locais e degradação ambiental e social acelerada. A ausência dessas estruturas torna factível a "tragédia dos comuns" (HARDIN, 1968), ou seja, a prevalência de comportamentos oportunistas e descomprometidos com a sustentabilidade e o usufruto do patrimônio natural comum. E, no sentido contrário, também se destaca na literatura crescente evidência de que políticas ambientais e de desenvolvimento local tendem a ser mais eficazes quando há reconhecimento das formas de colaboração existentes, por via das muitas modalidades de associação imersas nos contextos socioculturais (JENTOFT; McCAY, 1995). O mesmo é dito quanto à busca e à valorização dos conhecimentos locais no planejamento e na implementação de projetos e na consequente manutenção das atividades incentivadas (PRETTY; WARD, 2001).

Sob outro prisma, ressaltam os estudos de Lima e Shirota (2005) e Guanziroli (2007), que indicaram haver correlação entre participação em associações diversas e acesso a crédito rural no Brasil. Em relação ao PRONAF, Guanziroli (2007, p. 320) referiu-se à análise de gestores do programa segundo a qual o controle que organizações de agricultores e de assistência técnica exercem na execução do programa contribuiria para reduzir a inadimplência.

Diante, portanto, da crescente importância que assumem as organizações locais, é necessário avaliar as condições concretas ou o contexto social em que se criam associações e como elas podem produzir os efeitos esperados do associativismo, especialmente propiciando o acesso a recursos e à participação política. Ou, até mesmo, efeitos contrários. Assim, no caso deste estudo, abordam-se as seguintes questões: Como e por que os grupos adotaram um mesmo formato institucional? Como esse formato foi apropriado pelos grupos em suas relações internas e externas? Quais os agentes principais com quem se relacionavam e qual seu poder de influência nessas relações e nas alocações de recursos pertinentes? Examinar essas questões também importa porque, além do problema do alcance dos resultados e dos riscos assumidos por seus protagonistas, há a pressão que a constituição apressada de associações pode exercer sobre os laços sociais pré-existentes, desestruturando-os ao invés de reforçá-los. 
2.2 História prévia de organizações rurais, motivações e objetivos

Dentre as associações aqui estudadas, houve, por certo, iniciativas mais espontâneas em sua formação, como o caso observado em uma área de quilombolas. Assim, manifestando-se quanto ao papel dos colaboradores externos na constituição de uma associação de remanescentes de quilombos no município de Salvaterra, na ilha de Marajó, uma dirigente entrevistada sublinhou precisamente o que lhe pareceu ter sido um processo compartilhado pelos moradores do lugar e em diálogo com vários promotores externos. Sua associação, assim como as duas outras congêneres no município, haviam-se formado por uma confluência de fatores comuns. Como explicou a presidente, havia originalmente um "grupo comunitário", criado em 1986, cujos membros, para atenderem suas demandas próprias, praticavam mutirões nas roças, segundo a tradição. Em seu nome, apresentavam também solicitações à Prefeitura. Todavia, o grupo esteve parado por alguns anos até ser despertado em 2000. Inicialmente, a partir de pesquisas institucionais sobre a história das comunidades, que revelaram ou confirmaram sua condição de remanescentes de quilombos, indicando que os ascendentes ter-se-iam refugiado nesse local há cerca de dois séculos (ACEVEDO MARIN, 2005). Esses estudos propiciaram a emergência de um novo processo identitário: "Antes nós tinha conhecimento da história, mas não sabia para que ela servia, o valor dela", argumentou a líder entrevistada.

Como se verifica em âmbito nacional, para obterem o reconhecimento de seu estatuto, essas comunidades tinham recebido o apoio de organizações não governamentais como o Centro de Defesa do Negro no Pará (CEDENPA). Nesse percurso, fundaram então a Associação de Quilombolas. Nas etapas seguintes de sua constituição, a entrevistada mencionou a intervenção institucional do Instituto Nacional de Colonização e Reforma Agrária (INCRA), prevista nas normas administrativas desse órgão. No caso, a atuação do órgão, ao regularizar a disputada situação fundiária - uma das necessidades prementes dos moradores - registrou e legitimou o território tradicionalmente construído por seus ancestrais, mas negado pelo latifúndio da ilha: "Nós, como associação, tem mais peso para lutar. Essas terras aqui é da comunidade, mas os moradores da Fazenda S. M. cercaram a área e encurralou a comunidade" (Açaizal).

Assim, o caso indica o caminho de constituição de uma associação que era parte de um processo mais amplo de reorganização local, que 
incluía a revalorização das identidades locais e de suas práticas, bem como o apoio a uma necessidade crucial dos moradores, que era a segurança na posse da terra. Tudo isso associado a uma conjunção de "parceiros" externos, governamentais e não governamentais, que atuavam em processos de reconhecimento de grupos quilombolas nessa região e no país.

Em geral, entre os grupos estudados, não havia forte tradição de associações formais. Mas, algumas se originaram de uma associação de moradores ou de um grupo comunitário - tal como os quilombolas acima referidos -, grupos esses que foram redefinidos para se moldarem às oportunidades dos anos 90, com o FNO e, posteriormente, com o PRONAF. Detectou-se que, embora um pouco diferentes quanto aos seus fundamentos imediatos, as associações anteriores também haviam surgido para buscar melhorias para as localidades, misturando-se motivações de ordem econômica e de qualidade de vida. Invariavelmente a precariedade de condições de vida no local foi apontada como móvel. Um ponto comum a essas experiências associativas foi o fato de se terem desarticulado após algum tempo e cessado o estímulo inicial. $O$ trecho a seguir é claro nesse sentido. Alude à associação que existia anteriormente no bairro e à que estava ativa no momento da pesquisa, que administrava os financiamentos que a associação recebera:

Nós já tínhamos uma associação de moradores e... o objetivo era a gente ver se conseguia alguma coisa de benefício pra cá. Mas, a gente não conseguimos, não tivemos assim um caminho, alguém que orientasse, que mostrasse [...] assim um curso, pelo menos pra parte das mulheres, essa parte de trabalhar com costura. E, então, criamos essa outra. Porque aí, nós fomos trabalhar, estamos trabalhando com financiamentos, produzindo o abacaxi (Bairro de Cima).

A Caixa Agrícola de Conceição, no município de Salvaterra, a mais antiga associação dentre as contatadas pela pesquisa, foi incentivada por um antigo programa da Secretaria de Agricultura do Estado, na década de 80 . O programa visara fomentar a criação de unidades cooperativas rurais, denominadas "caixas" agrícolas e pesqueiras. Após alguns anos de funcionamento, a organi-zação entrou em dormência, tendo ressurgido com o recente estímulo do Governo do Estado, por intermédio da EMATER, ao cultivo de abacaxi e à implantação de uma fábrica de beneficiamento dessa fruta no município, para diversificar a economia da ilha de Marajó. Fazia parte desse estímulo a concessão de financiamentos 
aos novos produtores e a modernização do plantio, a fim de suprir a indústria. Foi com base nesse incentivo que as associa-ções de agricultores surgiram no município ou adotaram o formato que exibiam em 2005. O depoimento da dirigente deixa clara a influência das políticas governamentais, em suas oscilações, no impulso e no refluxo associativo:

As frutas aqui não tinha como trazer da roça... era aquela dificuldade.. Ela [Secretaria de Agricultura] doou o caminhão e o barco pra levar pra Belém... Era a única associação que tinha aqui.

[...] Só que, depois, não deu certo... Depois já veio a outra fábrica de abacaxi... Depois não deu certo a fábrica. Mas, só que na época que a fábrica veio pra cá, a Caixa Agrícola já tava assim meio devagar, né? E agora voltou de novo o crédito no Banco. Ela [Caixa Agrícola] ficou como avalista no Banco do Brasil, Banco do Basa também... Tem vários produtores que foram beneficiados através dela (Conceição).

Outro dirigente no mesmo município compartilhava essa visão das políticas de fomento:

Aqui, antes, era mandioca e milho e os derivados, como jerimum, maxixe, melancia. O grosso era para o consumo. [...] Bem, nós mudamos pro abacaxi. É pelo fato de dar sustentação pra indústria. [...] Ela foi montada, mas funcionou assim parcelado, fases de um mês, dois meses, já há dois anos e agora este ano não se sabe se ela vai funcionar. Espero que sim, né? (Bairro de Cima).

Dois dirigentes nos municípios de Abaetetuba e de Bragança apontaram mudanças de rumo muito parecidas para suas respectivas associações:

Ela nasceu como de moradores. Há quatro anos atrás nós transformamos em associação de agricultores. [...] Nós precisávamos de liberação de projetos no banco. Ela só foi ter atividade quando trocamos para associação dos agricultores (Rio Novo). Em 89 fundamos a associação. Mas, a gente ficou só no papel como se diz... Aí nós ficamos, ficamos, depois nós começamos a entrar em contato com a Pastoral do Pescador em Bragança, que tinha um rapaz que representava lá, o L., aí nós começamos a tratar com ele desse negócio de financiamento. Aí nós começamos a participar de umas reuniões em Capanema, em Castanhal [municípios paraenses], mas ficou sempre no papel... 
Passou uns tempos, quando foi em 98, tinha política, aí eu fui trabalhar com o Seu L., negócio de voto pra ele... Aí, começou a me incentivar e foi que nós tomamos iniciativa e fomos financiados (Farol).

São depoimentos que apontam, de um lado, as flutuações dos programas de desenvolvimento rural nas áreas de ocupação antiga no Nordeste paraense e, de outro lado, indicam a presteza das populações locais para responder aos estímulos públicos e tentar enquadrar-se nas condições estabelecidas para o acesso. A fragilidade das organizações formais foi evidenciada pela característica comum de se desestruturarem ou de entrarem em dormência, passados os estímulos e mecanismos de apoio. Mas a capacidade de criar associações, como visto, permanece.

\subsection{Os caminhos das associações recentes na região}

Dentre as associações surgidas a partir da década de $90 \mathrm{com}$ objetivos de dinamizar as atividades econômicas, é notória, portanto, a busca de crédito por meio de políticas que estabeleciam como pré-requisito a filiação a uma associação. Em um município específico, como foi dito, o Estado desenvolveu ações para a implantação de uma unidade processadora de frutos, e a oferta de crédito a pequenos agricultores associados, tendo como agente o PRONAF, seria a contrapartida para o desenvolvimento planejado.

Processo similar verificou-se em relação ao FNO para a agricultura e a pesca, que também foi endereçado a beneficiários por meio de associação, como indicou o dirigente de uma das associações mais antigas do município de Bragança: "Teve um projeto, esse projeto do FNO de 93. E aí só podia... o pequeno agricultor só podia ter acesso ao banco se fosse por intermédio de uma associação" (Taperal).

A associação estimulou o surgimento, mais tarde, de associações no seu entorno com a mesma motivação:

Olha, primeiro ela se organizou pra Taperal [...] Veio um projeto pra laranja, de coco, de feijão. A gente plantava, mas, era assim, cada qual plantava o seu. Aí nós achamos por bem, porque lá tinha essa associação. Aí foi que a gente reuniu o povo, os vizinho, os agricultor e é, criamos essa associação nesse localzinho chamado Patal. E temos muitas dificuldades na condição de plantagem de feijão, da mandioca, o agricultor (Patal). 
Verificou-se, desse modo, que programas de fomento econômico incentivaram as associações e, portanto, teoricamente abriram espaço para uma participação dos destinatários, isto é, pescadores, agricultores, extrativistas e artesãos, na condução dos programas, desde que constituídos em associações. Todavia, as ações de financiamento, que obedeciam a formatos pré-definidos e aplicados sem que os critérios fossem suficientemente claros para os clientes, não contribuíram para fortalecer as organizações locais. Frequentemente foi o contrário que ocorreu. Em primeiro lugar, criava-se espaço para uma participação controlada por forças políticas exteriores, agências governamentais, políticos ou entidades sindicais. Essas últimas, dados os problemas de inadimplência que se manifestaram desde o início, pressionavam o governo para rever os termos das concessões, bem como para ampliar o acesso das associações aos programas.

Especificamente no caso das colônias de pescadores, como se verá adiante, elas assumiram o papel de indicar beneficiários do crédito aos agentes financeiros, em razão da credibilidade da organização profissional e de sua competência para atestar o exercício da atividade. Elas influíram diretamente na criação de associações, reunindo nomes de sócios prováveis, convocando reuniões nas localidades e encaminhando as listas aos órgãos de extensão rural, visando à elaboração dos planos de crédito.

Do ponto de vista das associações locais, a falta de clareza quanto aos mecanismos dos financiamentos e a relativa rapidez com que se criaram ou se reestruturaram deram margem para desconfianças e, com o tempo, descrédito em relação às próprias associações. Os entrevistados assinalaram problemas de desconfiança interna entre os sócios, destes em relação à atuação de dirigentes e, finalmente, quanto ao papel das entidades sindicais no processo. O presidente de uma associação de agricultores assim descreveu esse tipo de atitude, bastante comum conforme os depoimentos:

Teve muitos moradores que disseram assim "Ah, eu não vou", porque nós não tinha recurso, né? [para registrar estatuto] A gente fizemos uma coleta aí pra legalizar, aí eles falaram "Ah, eu vivo sem associação, por que eu não vivo sem essa agora? Pra que isso? É só pra arrumar recurso pra ele, pra um, dois" (Bom Reduto).

Tal situação guarda semelhanças com a análise de Lima (2001) de uma experiência de política pública participativa de geração de emprego e renda no Nordeste brasileiro. Tratava-se do estímulo à formação de cooperativas artesanais para abastecer plantas industriais. A falta de 
transparência quanto aos termos do acordo para o conjunto de atores envolvidos, mostrou o autor, fez com que a iniciativa de formar uma cadeia produtiva aparecesse aos cooperados como simples oferta de mãode-obra barata para empresas. Não se constituíra a confiança que sustentaria o empreendimento. Lima (2001) chamou a atenção para a necessidade de clareza de normas e, em especial, de mecanismos de comunicação nos esforços para desenvolver arranjos produtivos horizontais entre parceiros desiguais em poder e recursos.

Da imposição de formas institucionais próprias como meio de acesso aos recursos disponíveis resultavam associações que podiam ser consideradas meramente formais, instrumentos para pleitear crédito rural ou algum serviço ou equipamento para a localidade. Em suma, resumiamse a um contrato estabelecido entre entidades - uma instituição financiadora, uma executora e uma associação.

Por outro lado, dadas as exigências iniciais e os caminhos jurídicos e burocráticos a percorrer para conseguir os fins, muitas associações não chegavam a representar um instrumento de ação coletiva eficaz. De fato, os entrevistados frequentemente se referiram a ocasiões em que ficaram sem meios de levar adiante as tarefas: "Eu participava das reuniões lá na Câmara. Aí solicitava pedido, fazia abaixo-assinado. 'Sim, agora o documento, se é uma associação'. 'É uma associação!' 'Então, por favor me dê o estatuto!'‘a gente não tem!' 'Então, a gente não pode fazer nada!’’ (Vila Azul).

O fato de se criarem associações locais, isto é, organizações voluntárias que reúnem pessoas que partilham uma situação ou uma condição social - necessidades e anseios comuns, pertencimento a uma mesma categoria profissional - não as isentava de se vincularem a redes de dependência de tipo clientelista. Ao contrário, os dados sobre as trajetórias contêm muitas evidências de práticas clientelistas, em que recursos públicos foram repassados, ou prometidos, através de canais controlados, que reproduziam o aspecto do favor e da dependência. Nesse caso, o estímulo ao associativismo produzia um efeito inverso ao que teoricamente deveria produzir, pois, ao invés de reduzir dependências pessoais, otimizava seus mecanismos, uma vez que um determinado provedor fazia um atendimento a uma associação, mas atingia os sócios mediante o velho pagamento em lealdade e reconhecimento. Esse aspecto de continuidade de práticas de dependência no interior dos espaços associativos tem relação com o que foi apontado por estudos sobre 
associativismo em contextos de grandes desigualdades sociais e políticas, como ocorre na sociedade brasileira. É o caso dos trabalhos de Kerstenetzky (2003) e de Reis (1995), referidos no início deste artigo. Em suas análises, as autoras questionavam a capacidade do associativismo de se contrapor às desigualdades vigentes, chamando a atenção para os efeitos mais significativos que políticas públicas de redistribuição podem ter, quer na redução das desigualdades, quer no fomento ao associativismo.

$\mathrm{Na}$ busca da sobrevivência do grupo, era então racional trilhar o conhecido caminho de buscar apoio junto a políticos, a despeito dos custos sociais, como destaca o segundo trecho abaixo, custos que levavam os membros do grupo a avaliar se aceitavam ou não a ajuda. As associações, portanto, não estavam modificando em seu favor as relações de poder no contexto em que operavam. Em geral, não dispunham de força social ou política para tal, como expressaram os entrevistados. Ao contrário, os líderes procuravam agir ajustando-se às relações e às posições sociais estabelecidas naquele contexto, de maneira a manterem a associação, ainda que em posições subordinadas: "Foi difícil tirar o CNPJ, porque a associação não tinha fundo para pagar. Daí eu fui com o vereador C." (Monsenhor); "Eu tenho recebido proposta de políticos para ajudar a associação. Eu converso com as pessoas sobre isso, porque a gente não quer depender..." (Vila de Cima).

Refletindo sobre as fragilidades das experiências de movimentos sociais no Brasil ao final da década passada, Telles (1999) argumentava que elas ocorriam no "terreno minado das práticas autoritárias enraizadas". O quadro traçado também se ajusta aos caminhos que as associações pesquisadas percorriam. Havia uma camisa de força institucional que, sobretudo de início, envolvia viagens e passos burocráticos custosos em tempo e dinheiro, o que ampliava as dificuldades, sobretudo quando a associação não era suficientemente coesa ou organizada para levantar os recursos necessários. Déficits de informação aumentavam os custos e criavam situações referidas pelos entrevistados como um "ir e vir sem fim".

Com tais problemas de origem, as associações buscavam o crédito que, por sua vez, fora formulado sem diálogo, com repercussões significativas, dentre as quais se destaca a descrença na associação, por parte dos próprios envolvidos. 
2.4 Restrições das políticas de fomento e seus reflexos sobre as associações

Como observado, a maioria das associações pesquisadas surgiu, ou se ajustou a um novo modelo - por exemplo, passando de associação comunitária para associação de agricultores -, na expectativa de obtenção de crédito. Muitas vezes, especialmente as associações de pescadores, formaram-se unicamente para se candidatarem ao financiamento, reunindo o número mínimo de pessoas requerido para tal. O problema é que o processo levava pessoas sem laços significativos entre si a se associarem, deixando de se verificar a confiança mútua que está na base do associativismo legítimo, ressaltado na literatura.

As entidades sindicais, que discutiam com os agentes financeiros a política de crédito, interferiram também diretamente na criação de associações. Vale ouvir o dirigente de uma associação de pescadores que, ao narrar a história da associação, indicou a existência de um vínculo anterior 'com os movimentos' e com a Federação de Trabalhadores na Agricultura, ao mesmo tempo que ressaltou a importância da organização da categoria para o êxito da empreitada: "A gente já via a necessidade de organizar a classe dos pescadores". Evidentemente, essa perspectiva não era suficiente para construir de imediato uma associação com poder de ingerência na condução dos financiamentos. Suas opiniões coincidem amplamente com as expressas por dirigentes de associações de pescadores nos quatro municípios alvo da pesquisa: "Aqui foram financiados doze barcos de três toneladas e mais um custeio, para equipar outra embarcação, com apetrechos e motor. O pessoal ficou perdido e não pagou. Era fundo perdido e diziam que não era para pagar. Aí, nós conseguimos renegociar" (Jutaî).

Entre os problemas apontados em localidades pesqueiras, está o fato de que os financiamentos não foram precedidos de discussões sobre a viabilidade de embarcações do porte pré-estabelecido nas condições locais. Frequentemente as reclamações referiam-se à necessidade de barcos de tonelagem maior para cobrir os custos ampliados de captura. Por outro lado, alternativas também não encontraram eco na definição dos itens financiáveis nos programas então vigentes, como a ideia de aquisição de um chamado 'barco-mãe' que acompanharia os barcos pequenos no interior da baía de Marajó. Esse barco maior recolheria o fruto das capturas para levar quotidianamente ao mercado da capital ou de outras cidades do Nordeste paraense, permitindo-lhes então diversificar os portos de desembarque sem necessidade de interrupção das pescarias. 
No tocante às associações agrícolas, os depoimentos também enfatizaram o distanciamento entre as condições do financiamento e as peculiaridades locais, o que gerou dificuldades que repercutiam nas relações intra-associações. Os dirigentes, repetidas vezes, sublinharam os limites da assistência técnica recebida e a necessidade de troca de informações. Tais situações foram caracterizadas por Maneschy e Klovdahl (2007) como evidências de lacunas de comunicação entre os vários intervenientes, agências de fomento, organizações sociais e associações locais. Os estudos analisados por Guanziroli (2007) apontaram limitações similares quanto à assistência técnica rural em diversas regiões do país. Os testemunhos a seguir, colhidos em duas associações no município de Bragança, exprimem percepções correntes entre os líderes sobre esse tipo de obstáculos:

Não sei como foi que ninguém acertou o plantio. Porque eles vieram, vieram estudar... nos ensinar, né? Mas, pra cá, quando é verão, é verão! Não tinha como nós regar essas plantas todas (Lago do Meio).

Esse Banco pagou pra gente as mudas que chegavam, os insumos todinhos. Só que com o decorrer do tempo, isso não deu certo. Foi feito um exame de solo aqui e o solo era... é arenoso. Não deu certo pro tipo de planta que a gente plantava. [...] Era pra ter muita laranja aqui, mas não deu. [...] Mas a associação permaneceu de pé! (Rio Virado).

Em todas as associações investigadas, o índice de inadimplentes do crédito era quase total, reflexo do que ocorria no Estado como um todo, o que motivou inúmeras reuniões, renegociações e protestos, especialmente incluídos nos Gritos da Terra anuais, realizados na capital do Estado inicialmente. Essas questões passaram a fazer parte da agenda do movimento sindical rural em todo o país.

No caso da pesca, menciona-se o agravante de um antigo problema na região, o roubo de redes no mar, que contribui para o endividamento (LOUREIRO, 1985). Ademais, ocorreu a deterioração acentuada dos barcos, motores e redes inadequados, quando não de qualidade duvidosa, de acordo com os entrevistados. No decorrer dos processos de renegociação das dívidas, coordenados por entidades como o Movimento de Pescadores do Pará e com participação das colônias de pescadores, chegou-se a fazer o repasse de barcos de pescadores em dificuldades para pagar a outros pescadores, que assumiram os compromissos. Mas, segundo os informantes, sócios que perderam o barco, obrigados a 
transferir a outros, por impossibilidade de continuarem pescando e pagando a dívida, questionavam a medida. Além disso, registraram-se críticas segundo as quais os valores do crédito foram insuficientes para cobrir as despe-sas nos estaleiros onde os barcos eram feitos e, finalmente, os valores estipulados para custeio das primeiras viagens eram irrisórios. Por conseguinte, a maioria dos financiados começara a utilizar os equipamentos “já na mão do atravessa-dor”, uma expressão habitual entre os entrevistados. Eis uma contradição a um dos principais objetivos do crédito - promover a autonomia do pescador em relação aos comerciantes. Aliás, tanto entre agricultores quanto entre pesca-dores, persistia a falta de meios para escoar o que era produzido, ampliando-se a dependência em relação aos atravessadores e, mesmo assim, provocando-se perda de produtos, como tinha acontecido com "muita laranja e muito coco" em um dos municípios.

Do mesmo modo como se verificou inadimplência quase generalizada de pescadores junto aos bancos, verificou-se também o descumprimento das contribuições financeiras estipuladas dos sócios para as associações, na forma de mensalidades, ou em percentuais dos produtos comercializados. Em suma, muito mais problemas que soluções e a concentração absoluta dos esforços de tantas associações nas questões relativas aos financiamentos.

O conjunto de problemas resultantes da forma como foram criadas as associações e os limitados recursos a que tiveram acesso suscitaram inevitáveis desconfianças e desinteresse. A título de exemplo, durante uma entrevista para esta pesquisa, ao responder à pergunta "As associações podem ajudar na participação democrática?", o diretor de uma associação e presidente do sindicato de trabalhadores rurais afirmou que uma associação era criada para a construção de um bem coletivo. Porém, ele também concluiu: “[...] associação não tem coletividade, é muito individualista. As pessoas só pensam em si próprias e não em um bem comum. Aqui não se cria associação para que haja uma solidariedade, a economia solidária".

A avaliação ecoa nas palavras de um dirigente de associação de quilombolas em Abaetetuba, ao criticar a participação dos colegas de direção: "Os membros da diretoria ainda pensam muito na individualidade. Eles não têm espírito de coletividade" (Arituba).

Em tal contexto, compreende-se que antigas representações sobre inabilidade ou desinteresse de grupos camponeses para se organizarem coletivamente, ou sobre o suposto individualismo próprio de pescadores, 
tenham ganhado novo fôlego. Nas associações de pescadores, foi frequente o fato de que, no início, por estímulo de técnicos de extensão rural, foram feitas tentativas originais de estimular a criação de um fundo comum para a entidade, por meio da destinação de parte do valor das capturas. No entanto, apenas uma associação de pescadores ainda mantinha essa prática no momento da pesquisa. Os desapontamentos eram comuns entre os dirigentes: "O pescador artesanal é uma classe desorganizada, pois quando eles foram financiados e começaram a pagar uma taxa para associação, mas eles diziam que o dinheiro era para o presidente. Então, começaram a ficar desinteressados" (Farol).

Uma associação, que foi fundada em 1993 e, em 1997, obteve o financiamento por via do FNO, identificou os problemas de administração dos recursos destinados à associação:

[...] aí escangalhou a associação porque a gente tirava vinte centavos [por quilo de pescado desembarcado], nós pegava o peixe, o presidente pegava o peixe, passava pro atravessador pra ganhar vinte centavos. E os presidentes que ficaram nesse tempo, não souberam fazer a coisa. Os vinte centavos pra eles, eles pensavam que eram muita coisa, aí depois se tornou ruim [...] Aí ninguém mais tirou a produção da associação, aquela comissão (Vila Caju).

A situação do presidente de uma associação que se encontrava, no momento da pesquisa, pescando em outro município - distante três horas por estrada - ilustra uma característica própria dos pescadores do litoral paraense, que é a mobilidade geográfica. Deslocam-se em razão dos ciclos sazonais das marés e das estações, que afetam a produtividade pesqueira nessa área costeira e estuarina. Tal mobilidade representa um desafio a mais para a concretização das associações. Requer força de vontade e persistência dos líderes e membros mais ativos para coordenar a participação.

Os entrevistados enfatizaram a difícil articulação das distintas experiências locais e o relativo fechamento dos grupos nos seus próprios projetos e preocupações. A seu ver, isso comprometia o papel das associações de fomentar a participação política dos agricultores. $\mathrm{O}$ presidente de um sindicato de trabalhadores rurais, entrevistado, criticou o fato de muitas terem sido criadas por intermédio de "grupos de interesses" e mostrou-se pessimista quanto ao futuro: "vai acabar as associações por falta de credibilidade". 
Deve ainda ser registrado que não se observou, no caso dos créditos para a pesca, a partir dos muitos relatos colhidos em campo, preocupações sistemáticas das agências quanto à adequação do esforço de pesca, ampliado com o emprego das novas embarcações e redes, à capacidade dos estoques para suportar tal esforço. Esse aspecto é indispensável em projetos de desenvolvimento social, como é o caso dos financiamentos para pequenos produtores de pesca. Com base nas entrevistas, ficou claro que se tratava do que se convencionou chamar 'pacotes', no sentido de pouco flexíveis ou sujeitos a discussão, com itens que nem sempre eram o necessário em certa localidade ou para grupos específicos de pescadores. Ao invés de aumento de capacidade produtiva - a orientação prevalecente no crédito pesqueiro -, a necessidade maior podia dizer respeito aos limitados meios de escoar o produto, ou ao capital de giro, ou à reforma de equipamentos, ou à vigilância contra roubos no mar, entre outras, a julgar pelos depoimentos de pescadores e pelos próprios planos futuros das associações. Como corolário, foi frequentemente assinalada a ingerência de intermediários - desde dirigentes sindicais até representantes comerciais - interessados na condução dos financiamentos segundo o padrão vigente. Faltou o diálogo entre as instituições de fomento, os sindicatos e as comunidades, para levantar as necessidades de modo mais participativo.

Os dividendos desse vício de origem manifestam-se no grande número de associações cujos sócios haviam-se afastado totalmente, deixando os dirigentes praticamente sós no seu esforço de manter ainda que formalmente a entidade, até que recomeçassem os pagamentos das dívidas, e fosse possível empreender novas atividades. Sempre havia a esperança de obter novos financiamentos, ou de encetar alguma atividade geradora de renda; daí o interesse em manter a associação viva. Quando os dirigentes precisavam viajar até a cidade ou à capital do Estado para alguma providência burocrática, tinham de "fazer coletas" junto aos sócios ou, então, solicitar ajuda a alguém com disponibilidade de recursos, como um político ou um empresário local.

\section{CONSIDERAÇÕES FINAIS}

$\mathrm{Na}$ ocasião do levantamento, foi observado que as associações que estavam alcançando os melhores resultados econômicos, políticos ou culturais almejados, empenhadas em atividades outras além do crédito, eram as que tinham realizado, anteriormente a sua constituição, algumas 
atividades coletivas ou comunitárias - isto é, aquelas que já tinham praticado uma forma de associação envolvendo confiança mútua e compromisso efetivo. Ou, ainda, as que estavam inseridas em uma rede de colaboradores - órgãos públicos, ONG, movimentos sociais ou outros - capazes de ampliar os focos da ação coletiva e de carrear outros bens e serviços, além dos financiamentos. Dessa maneira, aparentavam estar mais bem habilitadas para enfrentar as novas exigências e para administrar os limitados e problemáticos recursos à disposição dos grupos associados. A esse respeito, merece atenção a iniciativa de cinco associações de agricultores que haviam implementado plantios coletivos, em terras próprias ou alugadas, para angariar fundos que aliviassem os agricultores no início dos plantios e evitassem a necessidade de vender o produto adiantado ao intermediário. Iniciativa similar foi encontrada em uma associação de pescadores que mantinha a prática de os pescadores destinarem parte das capturas para a venda na localidade, sob a responsabilidade da diretoria, suplantando até então os problemas de desconfiança no trato com dinheiro, tantas vezes referido.

O estudo mostrou que, na verdade, impostas ou induzidas, as associações muitas vezes não passavam de grupos formais. Nessas condições, o associativismo - isto é, as relações de colaboração baseadas em confiança e vínculos significativos - não fertilizava a entidade. O compromisso entre os membros da associação era apenas subentendido, e não sancionado por um instituto costumeiro em vigência na comunidade. Do ponto de vista sociológico, que sentido podem ter, naquele contexto, ilações como "associação e democracia", "associação e participação cívica", na présuposição de uma afinidade entre os termos? Nos contextos analisados, parecia autoaplicável a atitude do free-rider, o dilema da ação coletiva destacado por Olson (1971), expresso na atitude daqueles que decidem não participar do esforço coletivo na medida em que podem, mesmo assim, beneficiar-se dos resultados desse esforço conjunto, já que são resultados com características de bem público. Trata-se justamente do tipo de benefícios que as associações estavam buscando, na forma de melhores condições de produzir e escoar os produtos, de alternativas de renda e de mecanismos de influência nas decisões de políticas de desenvolvimento local.

A prática e o êxito de uma forma de cooperação associativa e da qualidade das relações interpessoais no seu seio não dependem apenas dos indivíduos que as experimentam, mas, também, do ambiente social em que elas se dão; há ambientes propícios à cooperação leal e outros favoráveis ao individualismo, como bem ilustraram os estudos de Putnam 
(2005), por exemplo; há situações históricas de transição entre esses tipos de ambientes sociais, que comportam mudanças significativas que tornam mais complexas ou mais ambíguas as relações e as instituições sociais, como, por exemplo, a passagem do campo para a cidade, de uma vida tradicional para uma vida moderna, da passagem de normas de convivência ditadas pela tradição para normas de convivência estabelecidas por leis e por instituições do Estado moderno.

Um dos problemas enfrentados, então, pelos estudiosos da vida rural camponesa, em relação às formas de contrato estabelecidas entre instituições financeiras e produtores camponeses, seria em primeiro lugar, avaliar, diante de tantas distorções, sua validade e eficácia; em segundo, analisar em que condições, eventualmente, validade e eficácia poderiam verificar-se em fatos. Uma dessas condições, por certo, diz respeito à instituição de efetivos diálogos. A partir de então, em terceiro lugar, cabe buscar formas alternativas de contrato mais condizentes com as lógicas camponesas.

Este estudo localizado destaca o interesse de ampliar a base espacial da pesquisa sobre as experiências associativas no meio rural nesta região, um movimento que não dá sinais de arrefecer. Trata-se de buscar estabelecer correlações entre a formação das associações, suas trajetórias, as categorias envolvidas e os respectivos contextos históricos e culturais, entre os quais os tipos de estímulos que recebem e as redes sociais das quais derivam e nas quais operam.

\section{REFERÊNCIAS}

ACEVEDO MARIN, Rosa Elizabeth. Uso, condições de acesso e controle dos recursos hídricos em comunidades quilombolas do município de Salvaterra (ilha de Marajó, Pará). In: SEMINÁRIO INTERNACIONAL ÁGUAS DA PANAMAZÔNIA: Institucionalização de marcos regulatórios, visões de atores políticos e estratégias, 1., 2005, Belém. Anais..., Belém: UFPA, v. 1. p. 1-49. 2005

ALMEIDA, Alfredo Wagner Berno de. Universalização e localismo: movimentos sociais e crise dos padrões tradicionais de relação política na Amazônia. In: D'INCAO, Maria Angela; SILVEIRA, Isolda Maciel da (Org.). Amazônia e a crise da modernização. Belém: MPEG, p. 521-537. 1994.

BRASIL. Ministério da Integração Nacional; Ministério do Meio Ambiente. Plano Amazônia Sustentável. Brasília, DF, 2004.

CARVALHO, Horácio M. O campesinato no século XXI: possibilidades e condicionantes do desenvolvimento do campesinato no Brasil. Petrópolis: Vozes, p. 385. 2005. 
COLEMAN, James S. Social capital in the creation of human capital. American Journal of Sociology, v. 94, n. 8, p. 95-121, 1988. Supplement: Organizations and Institutions. Sociological and Economic Approaches to the Analysis of Social Structure.

CONTENTE, Simone. Armadilha do capital: a política de crédito agrícola especial sob a égide do capital financeiro. 2007. 91 f. Dissertação (Mestrado em Ciências Sociais) - Universidade Federal do Pará, Belém, 2007.

COSTA, Maria José Jackson. Trabalho, educação profissional e empregabilidade. Belém: UFPA, 2006.

DAGNINO, Evelina. Sociedade civil, espaços públicos e a construção democrática no Brasil: limites e possibilidades. In: DAGNINO, Evelina (Org.). Sociedade civil e espaços públicos no Brasil. São Paulo: Paz e Terra, 2002. p. 279-301.

DEGENNE, Alain; FORSÉ, Michel. Introducing social networks. London: SAGE, 1999.

D’INCAO, Maria Conceição. Clientelismo e democracia na organização dos agricultores familiares da microrregião de Marabá: a Associação dos Pequenos Agricultores da Consulta. Agricultura Familiar: Pesquisa, Formação e Desenvolvimento: revista do Programa de Pós-Graduação Agriculturas Amazônicas do NEAD, Belém, v. 1, n. 2, p. 113-139, 2000.

ESTERCI, Neide; LIMA, Deborah; LÉNA, Philippe. Diversidade sociocultural e políticas ambientais na Amazônia: o cenário contemporâneo. Boletim Rede Amazônia, Belém, ano 1, n. 1, p. 3-8, 2002.

GRAFTON, R. Quentin. Social capital and fisheries governance. Ocean \& Coastal Management, n. 48, p. 753-766, 2005.

GUANZIROLI, Carlos E. PRONAF dez anos depois: resultados e perspectivas para o desenvolvimento rural. Revista de Economia e Sociologia Rural, v. 45, n. 2, p. 301-328, abr./jun. 2007.

HARDIN, Garret. The tragedy of the Commons. Science, New Series, v. 162, n. 3859, p. 1243-1248, Dec. 1968.

HÉBETTE, Jean. Cruzando a fronteira: 30 anos de estudo do campesinato na Amazônia. Belém: EDUFPA, 2004.

HÉBETTE, Jean. Participation municipale en milieu rural dans l'Etat du Pará: ouverture institutionnelle et contraintes sociopolitiques. In: TEISSERENC, Pierre (Org.). La mobilisation des acteurs dans l'action publique locale: au Brésil, en France et en Tunisie. Paris: L'Harmattan, 2006. p. 33-48.

HÉBETTE, Jean. Para situar o associativismo nos seus respectivos contextos históricos. Relatório de pesquisa do projeto Estudo sobre Associações Rurais e Participação Politica na Amazônia Oriental (EPAR). Mimeografado. Inédito. 
HÉBETTTE, Jean; ALVES, Juliette Miranda; QUINTELA, Rosangela. Parentesco, vizinhança e organização profissional na formação da fronteira amazônica. In: HÉBETTTE, Jean; MAGALHÃES, Sônia B.; MANESCHY, Maria Cristina (Org.). No mar, nos rios e na fronteira: faces do campesinato no Pará. Belém: EDUFPA, 2002. p. 233-273.

JENTOFT, Svein; McCAY, Bonnie. User participation in fisheries management: lessons drawn from international experiences. Marine Policy, v. 19, n. 3, p. $227-$ 246, 1995.

KERSTENETZKY, Celia Lessa. Sobre associativismo, desigualdades e democracia. Revista Brasileira de Ciências Sociais, São Paulo, v. 18, n. 53, p. 131-142, out. 2003.

LAVALLE, Adrian Gurza; CASTELLO, Graziela; BICHIR, Renata Mirandola. Redes e capacidade de ação na sociedade civil: o caso de São Paulo, Brasil. Redes: Revista Hispana para el Analisis de Redes Sociales, v. 12, \#6, jun. 2007. Disponível em: <http://revista-redes.rediris.es>. Acesso em: 10 jul. 2007

LIMA, Jacob C. Teoria do capital social na análise de políticas públicas. Política $\&$ Trabalho, n. 17, p. 46-63, set. 2001.

LIMA, Roberto Arruda de Souza; SHIROTA, Ricardo. Influência do capital social no mercado de crédito rural. Revista de Economia e Sociologia Rural, Brasília, v. 43, n. 1, 2005.

LIN, Nan. Social Capital, A theory of social structure and action. Cambridge: Cambridge University Press, 2001.

LOUREIRO, Violeta R. Parceiros do mar. Belém: MPEG, 1985.

MAIA, Maria Lúcia Sá; NEVES, Maria Elizabete Coelho das. Conselho Municipal de Desenvolvimento Rural Sustentável no Pará: descentralização e participação municipal. In: HÉBETTE, Jean; MAGALHÃES, Sônia B.; MANESCHY, Maria Cristina (Org.). No mar, nos rios e na fronteira: faces do campesinato no Pará. Belém: EDUFPA, 2002. p. 329-353.

MANESCHY, Maria Cristina; KLOVDAHL, Alden. Redes de associações de grupos camponeses na Amazônia Oriental (Brasil): fontes de capital social? Redes: Revista Hispana para el Analisis de Redes Sociales, v. 12, \#4, jun. 2007. Disponível em: <http:/ / revista-redes.rediris.es>. Acesso em: 5 jul. 2007.

MENDRAS, Henri. Sociedades camponesas. Rio de Janeiro: Zahar, 1978.

MOREIRA, Edma Silva. Mouvement social pour la défense d'un territoire traditionnel à Porto de Moz (Amazonie brésilienne): une participation "par le bas". In: TEISSERENC, Pierre (Org.) La mobilisation des acteurs dans l'action publique locale: au Brésil, en France et en Tunisie. Paris: L’Harmattan, 2006. p. 59-72. 
OLSON, Mancur. The logic of collective action. Cambridge: Harvard University Press, 1971. 186 p.

PLUMMER, Ryan; FITZGIBBON, John. People matter: the importance of social capital in the co-management of natural resources. Natural Resources Forum, v. 30, n. 1, p. 51-62, 2006.

PRETTY, Jules; WARD, Hugh. Social capital and the environment. World Development, v. 29, n. 2, p. 209-227, 2001.

PUTNAM, Robert. Bowling alone: the collapse and revival of American community. New York: Simon \& Schuster, 2002.

PUTNAM, Robert. Comunidade e democracia: a experiência da Itália moderna. Rio de Janeiro: FGV, 2005.

REIS, Elisa P. Desigualdade e solidariedade: uma releitura do "familismo amoral" de Banfield. Revista Brasileira de Ciências Sociais, São Paulo, n. 29, p. 35-48, 1995.

ROBERTS, Brian. Globalization and Latin American cities. International Journal of Urban and Regional Research, v. 29, n. 1, p. 110-123, 2005.

ROY, Gérard. A agricultura familiar nas frentes de colonização da Transamazônica: ensaio crítico sobre as abordagens agroeconômicas. In: HÉBETTE, Jean; MAGALHÃES, Sônia B.; MANESCHY, Maria Cristina (Org.). No mar, nos rios e na fronteira: faces do campesinato no Pará. Belém, EDUFPA, 2002. p. 291-328.

SCHUURMAN, Frans J. Social capital: the politico-emancipatory potential of a disputed concept. Third World Quartely, v. 24, n. 6, p. 991-1010, 2003.

SILVA, Marcelo Kunrath. Sociedade civil e construção democrática: do maniqueísmo essencialista à abordagem relacional. Sociologias, Porto Alegre, ano 8, n. 16, p. 156-179, jul./dez. 2006.

SZRETER, Simon; WOOLCOCK, Michael. Health by association? Social capital, social theory and the political economy of public health. International Journal of Epidemiology, n. 33, p. 650-667, 2004.

TELLES, Vera da Silva. Direitos sociais: afinal do que se trata? Belo Horizonte: UFMG, 1999.

TURA, Letícia Rangel. Notas introdutórias sobre os fundos constitucionais de financiamento e sua configuração na Região Norte. In: TURA, Letícia Rangel; COSTA, Francisco de Assis. Campesinato e Estado na Amazônia: Impactos do FNO no Pará. Brasília, DF: Brasília Jurídica; FASE, 2002. p. 29-46.

WOOLCOCK, Michael; NARAYAN, Deepa. Social capital: implications for development theory, research and policy. The World Bank Researcher Observer, v. 15 , n. 2 , p. 225-247, Aug. 2000.

Texto submetido à Revista em 15.12.2007 e aceito para publicação em 23.04.2008. 